\title{
A Study of the Shear Response of a Lead-Free Composite Solder by Experimental and Homogenization Techniques
}

\author{
Journal Article \\ Author(s): \\ Sivasubramaniam, V.; Galli, M.; Cugnoni, J.; Janczak-Rusch, J.; Botsis, J. \\ Publication date: \\ 2009-10 \\ Permanent link: \\ https://doi.org/10.3929/ethz-b-000085656
}

Rights / license:

In Copyright - Non-Commercial Use Permitted

Originally published in:

Journal of Electronic Materials 38(10), https://doi.org/10.1007/s11664-009-0878-0 


\title{
A Study of the Shear Response of a Lead-Free Composite Solder by Experimental and Homogenization Techniques
}

\author{
V. SIVASUBRAMANIAM, ${ }^{1,2,4}$ M. GALLI ${ }^{3}$ J. CUGNONI, ${ }^{2}$ \\ J. JANCZAK-RUSCH, ${ }^{1}$ and J. BOTSIS ${ }^{2}$
}

1.-Laboratory for Surface and Joining Technology, Swiss Federal Laboratories for Materials Testing and Research (EMPA), Dübendorf 8600, Switzerland. 2.-Laboratoire de Mécanique Appliquée et d'analyse de Fiabilité, Ecole Polytechnique Fédérale de Lausanne (EPFL), Lausanne 1015, Switzerland. 3.-Department of Engineering, Cambridge University, Trumpington Street, Cambridge CB2 1PZ, UK. 4.-e-mail: venkatesh.sivasubramaniam@gmail.com

The current study proposes a combined experimental and modeling approach to characterize the mechanical response of composite lead-free solders. The influence of the reinforcement volume fraction on the shear response of the solder material in the joint is assessed. A novel optimized geometry for single lap shear specimens is proposed. This design minimizes the effect of plastic strain localization, leading to a significant improvement of the quality of experimental data. The constitutive model of the solder material is numerically identified from the load-displacement response of the joint by using inverse finite element identification. Experimental results for a composite solder with 0.13 reinforcement volume fraction indicate that the presence of the reinforcement leads to a $23 \%$ increase of the ultimate stress and a $50 \%$ decrease of the ultimate strain. To interpret experimental data and predict the elastoplastic response of the composite solder for varying particle volume fraction, a three-dimensional (3D) homogenization model is employed. The agreement between experiments and homogenization results leads to the conclusion that the increase in the ultimate strength and the decrease in ductility are to be attributed to load sharing between matrix material and particles with the development of a significant triaxial stress state which restricts plastic flow in the matrix.

Key words: Mechanical properties, shear test, lead-free, composite, homogenization

\section{INTRODUCTION}

Solders are widely used as interconnect materials in the electronics industry. The solder interconnect provides both electrical contact and mechanical connection between integrated circuit devices and their substrate. ${ }^{1}$ Traditionally used $\mathrm{Pb}-\mathrm{Sn}$ solders have to be replaced by Sn-rich lead-free solders because of the toxicity concerns surrounding the use of lead. Some potential replacements include $\mathrm{Sn}-\mathrm{Ag}$ and $\mathrm{Sn}-\mathrm{Ag}-\mathrm{Cu}$ solders. ${ }^{2}$ However a sufficiently extended knowledge of the mechanical behavior and

(Received January 20, 2009; accepted June 13, 2009;

published online July 7, 2009) reliability of Sn-rich lead-free solders is not yet available. ${ }^{3}$ A particularly critical aspect is reliability at high service temperatures. For instance, in automobile applications solder joints undergo combined electrical, mechanical, and thermal loads. Such microelectronic applications require solders to possess good microstructural stability, strength, and creep resistance. ${ }^{4}$

In the last decade, researchers have demonstrated the possibility to engineer composite lead-free solders with improved mechanical and thermomechanical properties. Composite solders contain uniformly distributed second-phase particles that reinforce the solder matrix. ${ }^{5}$ The two most common methods to produce composite solders are in situ and 
by mechanical addition. Between these two the mechanical addition of suitable particles that bond with the solder matrix appears to be the most viable. The densities of the particle and the solder matrix should be matched to avoid segregation and promote the uniform distribution of reinforcements. ${ }^{5}$ Moreover, the presence of the reinforcement should not significantly alter the reflow temperature and wettability of the solder matrix. ${ }^{5}$ Adopting the composite approach, Lee et al. produced composite solder by adding $0.1 \mathrm{wt} . \%$ to 2.0 wt. $\%$ Co $(<2 \mu \mathrm{m})$ particles to eutectic Sn-3.5Ag. They reported a $28 \%$ increase in the shear strength of the Co-reinforced Sn-3.5Ag solder compared with the unreinforced counterpart. This increase in the shear strength was attributed to the formation of faceted needle-like $(\mathrm{Cu}, \mathrm{Co})_{3} \mathrm{Sn}_{2}$ intermetallic compounds. ${ }^{6}$ Recent developments in nanotechnology have led researchers to produce nanocomposite solders by mechanically mixing Sn-rich lead-free solders with metallic nanopowders such as $\mathrm{Ni}$, $\mathrm{Cu}$, and $\mathrm{Mo}$. Such nanocomposite solders have been reported to possess enhanced mechanical properties. $^{7-9}$ Extensive research has been performed on composite solders, and the majority of the published results report an increase in strengthrelated mechanical properties such as ultimate tensile stress, shear strength, and microhardness. ${ }^{5}$ The enhancement of the mechanical properties can be associated with mechanisms occurring at two levels: (i) at the grain/dislocation level, the enhancement of the mechanical properties in composite solders is commonly attributed to pinning of grain boundaries that restrain grain boundary sliding occurring at higher homologous temperature and (ii) at the continuum level, the higher yield and ultimate stress of the composite material is usually justified by load sharing between the phases and subsequent development of significant triaxial stress state in the solder matrix that restricts plastic deformation. However, the dependency of the property (shear strength/creep resistance) enhancement mechanism on the reinforcing characteristics of particles such as volume fraction and size is not yet fully understood. ${ }^{10}$

Various testing methods have been used for investigating the mechanical properties of Sn-rich lead-free solders. ${ }^{11}$ Among these, shear testing is believed to resemble real-life loading configuration of the solder joints. ${ }^{12}$ A typical solder joint consists of a thin layer, or a small ball of solder, within a size range of $100 \mu \mathrm{m}$ to $1000 \mu \mathrm{m}$, confined between relatively rigid base materials. In such a structure, constraints from the rigid base materials induce inhomogeneous stress and strain fields in the solder. ${ }^{12,13}$ Due to the small thickness of the solder layer compared with the substrate, mechanical test methods in which only the global strains are measured (clip gage) and then corrected to take the deformation of the base material into account can only provide a crude approximation of the actual strain field in the solder. ${ }^{12}$ Local strain measurement on the length scale of the solder thickness (optical strain measurement) is thus highly recommended to characterize the solder material accurately. Moreover, Sn-rich lead-free solder joints exhibit an elastoplastic behavior, strongly dependent on factors such as joint geometry, dimensions, and processing parameters, all of which can affect the microstructure. ${ }^{12-16}$ In fact, very few studies have systematically investigated the effect of strain inhomogeneity and geometry dependence of the elastoplastic behavior of solder joints under shear. These studies report a large scatter in experimental results, even for solder joints prepared with the same solder alloy. ${ }^{12}$ Therefore the effect of stress and strain inhomogeneity on the shear response of the solder joint needs to be minimized as much as possible by careful test design and must be taken into account in the model used to identify the elastoplastic properties of the solder material. This precise determination of the mechanical response of the solder material is required to model and predict the reliability of solder joints and electronic packages successfully.

In an effort to address the above issues, the current study adopts a combined approach of experimental and modeling techniques. The primary objective is the assessment of the effect of reinforcement on the shear response of composite lead-free solder. For this purpose a reference Sn-4.0Ag-0.5Cu (SAC405) lead-free solder alloy and a composite solder prepared by adding micrometersized Ni particles to SAC405 solder were investigated. A novel specimen geometry, optimized using the finite-element (FE) method, is proposed. This design leads to "cleaner" shear tests, minimally affected by stress concentration and with a low risk of premature failure at the substrate/solder interface. As a consequence, reliable mechanical properties can be identified from experimental results. In situ optical extensometry combined with digital image correlation (DIC) is used to determine the stress-strain response of the solder joint. ${ }^{13}$ Finally, the constitutive properties of solder materials are numerically identified from the global stress-strain response of the solder joint by inverse FE modeling of the shear test.

A 3D FE homogenization model for particlereinforced composites is employed to predict the solder's elastoplastic behavior as a function of particle volume fraction. ${ }^{17}$ The inputs of the homogenization model are the constitutive model of the unreinforced solder matrix, and the elastic properties and volume fraction of the reinforcement, i.e., the phases formed due to particle addition. The output of the homogenization model is the uniaxial stress-strain curve of the composite solder. The homogenization results are then compared with the constitutive model of the composite solder identified from the experimental data. Finally, this comparison serves as a basis for a discussion of the 
effects of particle reinforcement in the present composite solder system.

\section{MATERIALS AND EXPERIMENTAL PROCEDURES}

\section{Fabrication of Bulk Specimens for Microstructure Analysis}

Lead-free solder SAC405 (Alpha Metals), in paste form, with OM338 flux, was utilized. The composite solder was prepared by adding 4.2 vol.\% micrometer-scale commercial $\mathrm{Ni}$ particles $(3 \mu \mathrm{m}$ to $7 \mu \mathrm{m}$, 99.9\% purity, Leico Industries) to the solder paste with a simple mechanical mixing method. ${ }^{18}$ The volume fraction of $\mathrm{Ni}$ particles was computed with respect to the actual volume of solder in the SAC405 paste, which contains about 10 vol.\% flux. Bulk specimens for microstructural analysis, of both the reference and composite solder, were fabricated by reflowing the prepared solder in a cylindrical aluminum nitride crucible. Reflow soldering was conducted in a Zelflow RO4 oven (LPKF Electronics) with a temperature profile consisting of a $170^{\circ} \mathrm{C}$ preheating stage followed by a peak temperature of $240^{\circ} \mathrm{C}$. The bulk specimens were reflowed individually and removed from the oven to cool in air at room temperature. The reflowed specimens were degreased with ethanol, rinsed in deionised water, blown dry, and embedded in epoxy resin for further metallographic preparation. The embedded specimens were polished to a $0.1 \mu \mathrm{m}$ finish with a suspension of alumina particles and finally etched with a solution of $5 \mathrm{vol} . \% \mathrm{HCl}$ in methanol to highlight the intermetallic phases. Optical and scanning electron microscopy (SEM) with energy-dispersive spectroscopy (EDS) were used to characterize the intermetallic phases and provide micrographs for subsequent image analysis.

The micrographs of the polished and etched bulk specimens were processed to estimate the volume fraction of $\mathrm{Ni}$ and $\mathrm{Ni}$-containing intermetallic phases. The average volume fraction was calculated from nine measurements on three composite specimens with identical composition.

\section{Design and Fabrication of Joint Specimens for Shear Testing}

Extensive FE simulations accompanied by preliminary shear tests were carried out to design the single shear joint specimen, sketched in Fig. 1. Its geometry was optimized to ensure almost uniform plastic strain at the center of the joining layer and minimal stress concentrations at the interfaces. Another important advantage of the developed shear test specimen is that its fabrication requires minimally invasive machining steps: only two 2-mm-diameter holes need to be drilled to obtain the final specimen geometry, as shown in Fig. 1. The drilling operations are performed in a specific clamping and alignment fixture which ensures

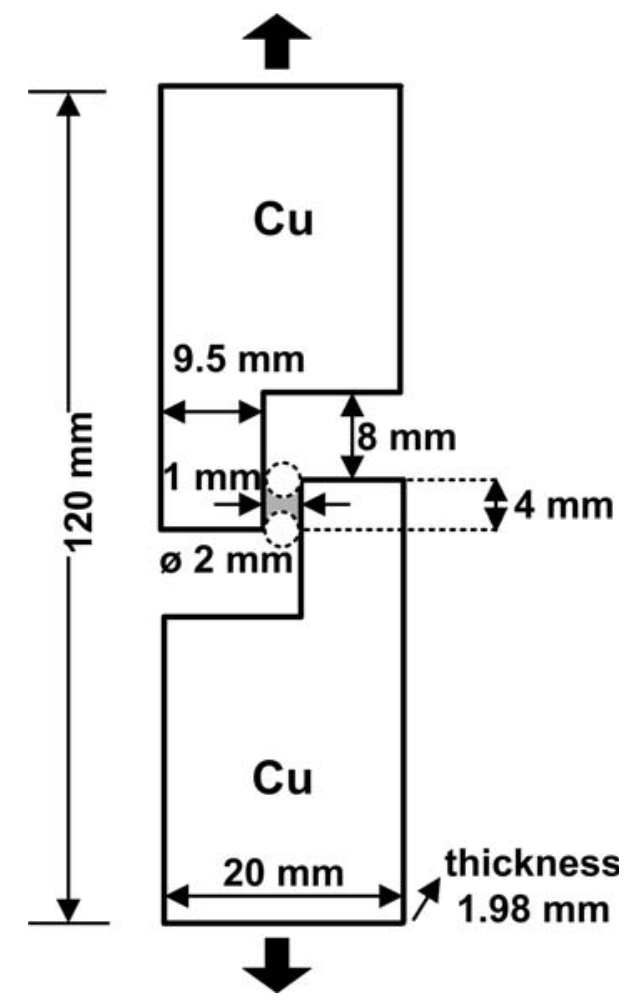

Fig. 1. Schematic of the novel single lap joint shear specimen and loading direction.

that the solder layer is not damaged during the operation. A typical equivalent plastic strain field obtained by FE simulations and an experimental shear strain field measured during shear testing, measured by DIC, are compared in Fig. 2a and b. It is worth noticing that, even in the presence of imperfections (e.g., voids), plastic deformation tends to concentrate in the center of the joining layer, thereby minimizing the possible effects of interface damage on the stress-strain response of the solder.

The solder joint specimens were fabricated according to the following procedure. $\mathrm{Cu}$ plates were machined to produce symmetrical substrates of dimensions $60 \mathrm{~mm} \times 20 \mathrm{~mm} \times 2 \mathrm{~mm}$. Individual shear lap joints were then produced by affixing the substrates to a custom soldering jig that ensures a gap width of $1 \mathrm{~mm}$, as shown in Fig. 1. The solder paste, prepared as described in "Fabrication of Bulk Specimens for Microstructure Analysis," was spread between the two $\mathrm{Cu}$ substrates. The solder was reflowed and the joints were produced by placing the entire assembly (jig with affixed $\mathrm{Cu}$ substrates and solder) in the reflow oven, where it underwent an identical temperature profile to that adopted for the bulk solder specimens. Once removed from the jig, the test specimens were carefully ground to remove any excess solder. The average specimen thickness after grinding was $1.98 \mathrm{~mm}$. A total of 22 specimens was produced: 12 with SAC405 and 10 with the composite solder. Four joints, two for each material, 

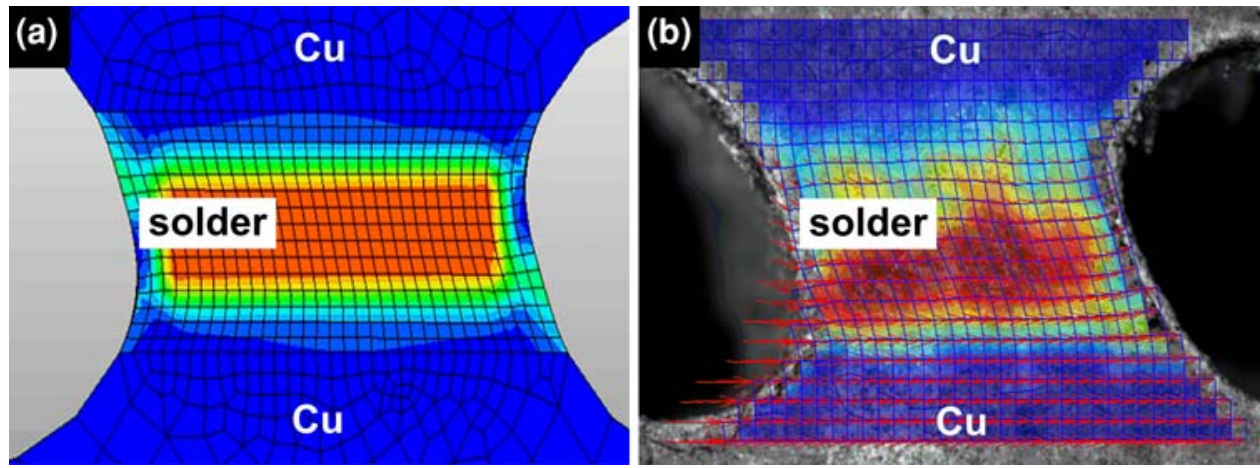

Fig. 2. (a) Simulated equivalent plastic strain field in the shear test specimen. (b) Shear strain field, as measured by DIC, during a shear test.

were metallographically polished to obtain micrographs for the analysis of the morphology and thickness of the substrate/solder reaction layer and to observe the deformation during shearing. The average reaction layer thickness at the substrate/ solder interface was determined by using the technique adopted in a previous study by the authors. ${ }^{19}$

Shear tests were performed on an Instron 5848 Micro Tester with an imposed displacement rate of $2 \mu \mathrm{m} / \mathrm{min}$. A sequence of high-resolution images of the joints was recorded during the test using an optical microscope at magnifications of $24 \times$ to $48 \times$. The recorded sequences were then processed with DIC software to calculate the evolution of the average strain in the solder joint during the test. ${ }^{13}$ This technique provides for a strain resolution in the joint of approximately $0.02 \%$.

\section{RESULTS}

\section{Microstructural Analysis}

The two materials investigated in the current study are referred to hereafter as follows: SAC405 stands for the unreinforced reference solder, while SAC405+Ni stands for the composite solder containing Ni particles.

The microstructure of bulk SAC405 was similar in morphology and composition to that reported in a previous study. ${ }^{19}$ The microstructure of a bulk SAC405+Ni composite specimen is presented in Fig. 3. The Ni particles have reacted with the solder alloy to form a surrounding reaction layer. The results of a typical EDS line scan for elemental weight composition versus scan distance $(\mu \mathrm{m})$ are reported in Fig. 4, while the corresponding path is indicated by the dotted line in Fig. 3. The graph indicates an unreacted core of $\mathrm{Ni}$ surrounded by a reaction layer. The weight composition of the reaction layer closely corresponds to the $\mathrm{Ni}_{3} \mathrm{Sn}_{4}$ intermetallic phase occurring at 73 wt. $\%$ Sn, ${ }^{20}$ (the matrix alloy is mainly composed of $\mathrm{Sn}, 95.5 \mathrm{wt} . \%$, with minor additions, 0.5 wt.\%, of $\mathrm{Cu}$ ). The average intermetallic layer thickness around the $\mathrm{Ni}$ particles is about $3.5 \mu \mathrm{m}$ and is characterized by "sunburst" morphology, as reported in analogous

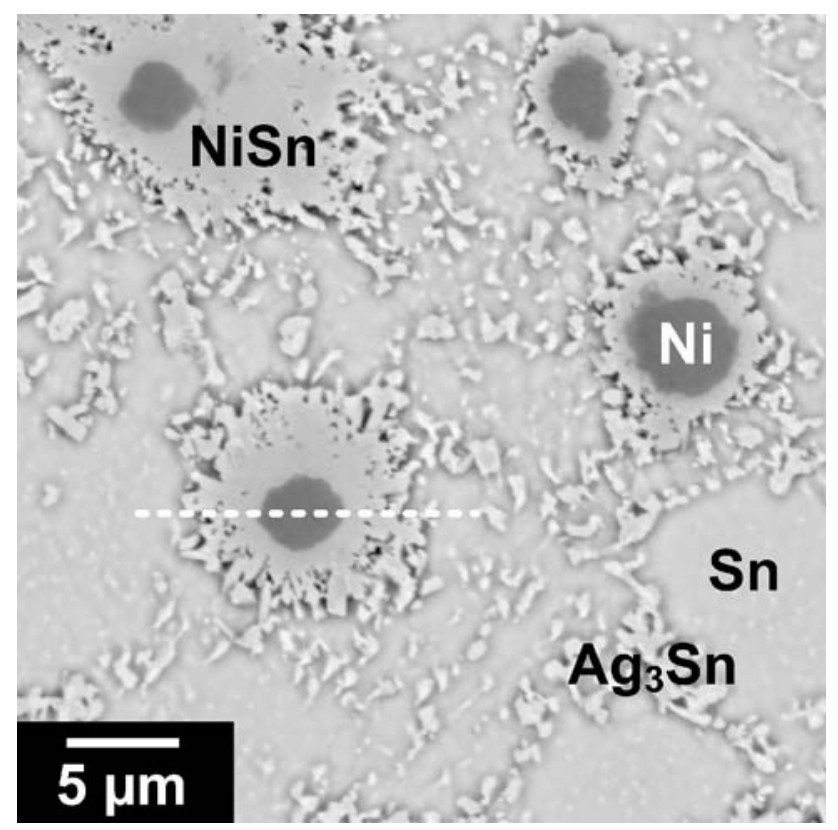

Fig. 3. Backscatter SEM image of bulk SAC405+Ni specimen at high magnification. The dotted line is the path of the EDS line scan reported in Fig. 4.

studies. ${ }^{21} \mathrm{~A}$ few larger $\mathrm{Ag}_{3} \mathrm{Sn}$ platelets and pores up to $5 \mu \mathrm{m}$ in diameter were also observed. The volume fraction of the reinforcing phases produced due to the addition of $4.2 \mathrm{vol} . \% \mathrm{Ni}$ particles was calculated by image analysis and found to be around $13 \%$. If all the $\mathrm{Ni}$ reacted, a volume fraction of about $16 \%$ would be expected (as estimated by the mass balance equation). This further observation confirms the observations in Fig. 3: much of the $\mathrm{Ni}$ in the particles has reacted to form $\mathrm{Ni}_{3} \mathrm{Sn}_{4}$ intermetallics, but in many cases a small core of unreacted $\mathrm{Ni}$ is still present.

The microstructural analysis of the shear test specimens produced with SAC405 revealed that the reaction layer (substrate/solder interface) consists of a scallop-shaped layer of $\mathrm{Cu}_{6} \mathrm{Sn}_{5}$ intermetallic with an average thickness of $3.3 \mu \mathrm{m}$. These results are in agreement with data reported in the literature. ${ }^{19,22}$ The microstructural analysis of the shear test 


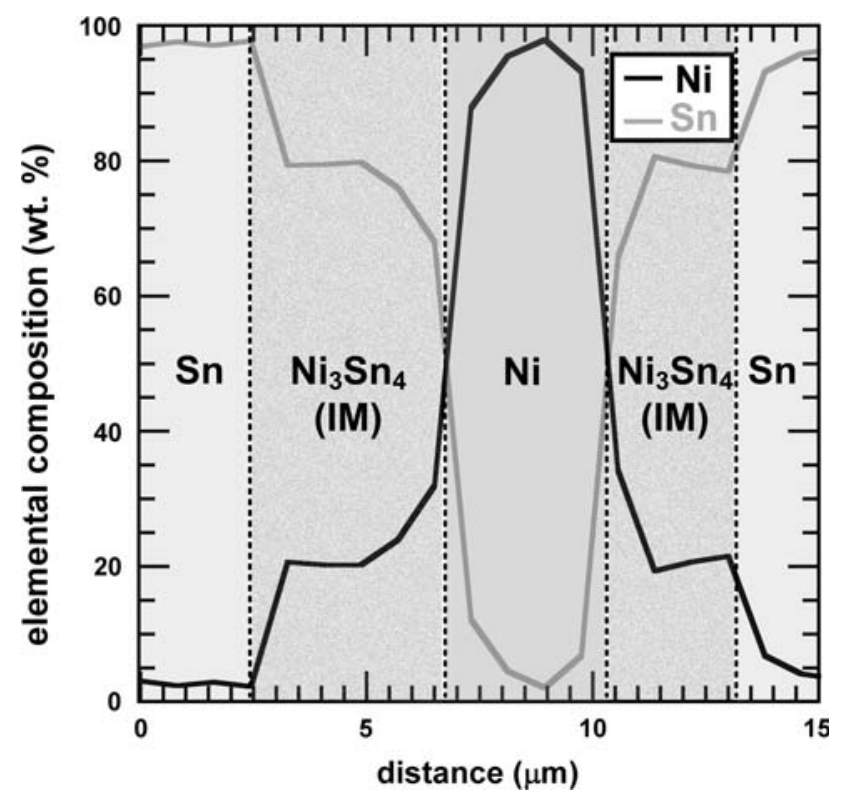

Fig. 4. Typical EDS line scan on SAC405+Ni specimen. The graph represents the evolution of elemental composition (wt.\%) along the path $(\mu \mathrm{m})$ indicated in Fig. 3.



Fig. 5. Backscatter SEM image of SAC405+Ni shear test specimen showing the intermetallic layer at the substrate/solder interface.

specimens produced with SAC405+Ni revealed an increased thickness of $10.1 \mu \mathrm{m}$ and a more planar morphology for the reaction layer, as shown in Fig. 5. Figure 5 also illustrates that $\mathrm{Ni}$ particles have reacted with the solder alloy and the substrate $\mathrm{Cu}$ ) to form a CuNiSn layer. Results from similar studies document the formation of CuNiSn intermetallic both at the substrate/solder interface and around $\mathrm{Ni}$ particles. ${ }^{21}$ Moreover it was observed

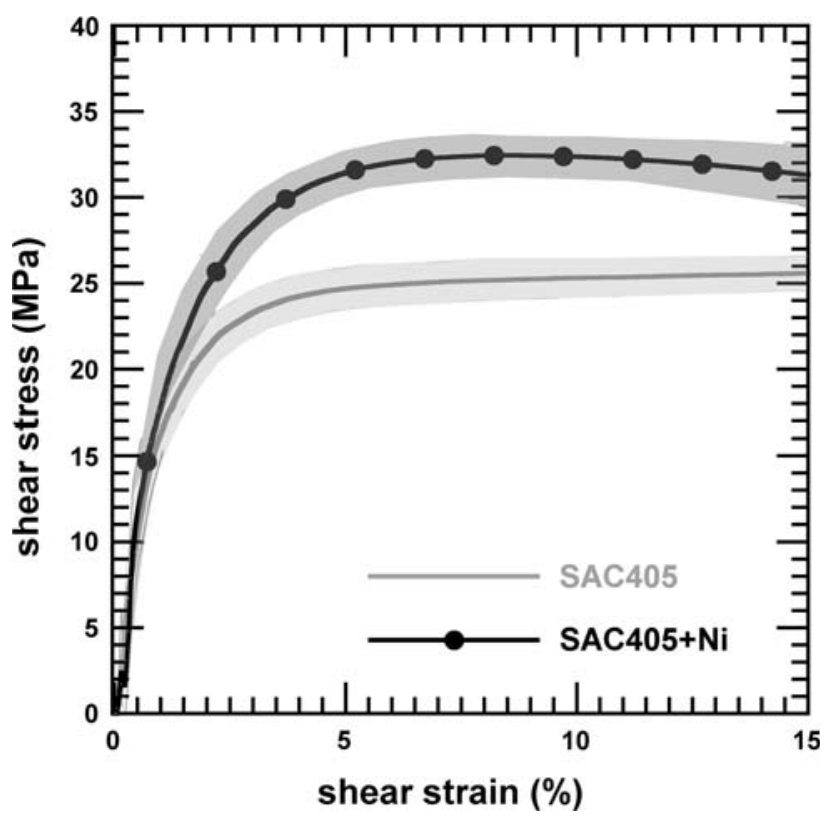

Fig. 6. Experimental stress-strain response of the joint specimens tested in shear.

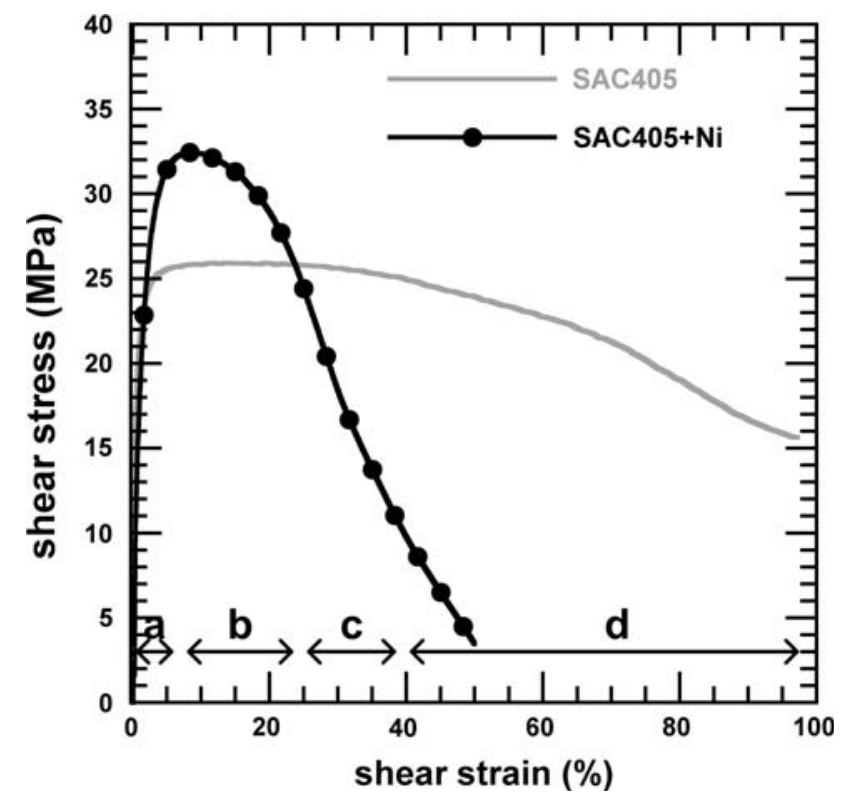

Fig. 7. Average experimental stress-strain response of joint specimens with different strain range.

that Ni-CuNiSn particles tend to form agglomerates, close to the substrate/solder interface, as shown in Fig. 5.

\section{Mechanical Characterization of the Solder Joint}

The stress-strain responses of the joint specimens tested in shear are presented in Fig. 6, in which the curves are plotted up to $15 \%$ strain, and Fig. 7 , 

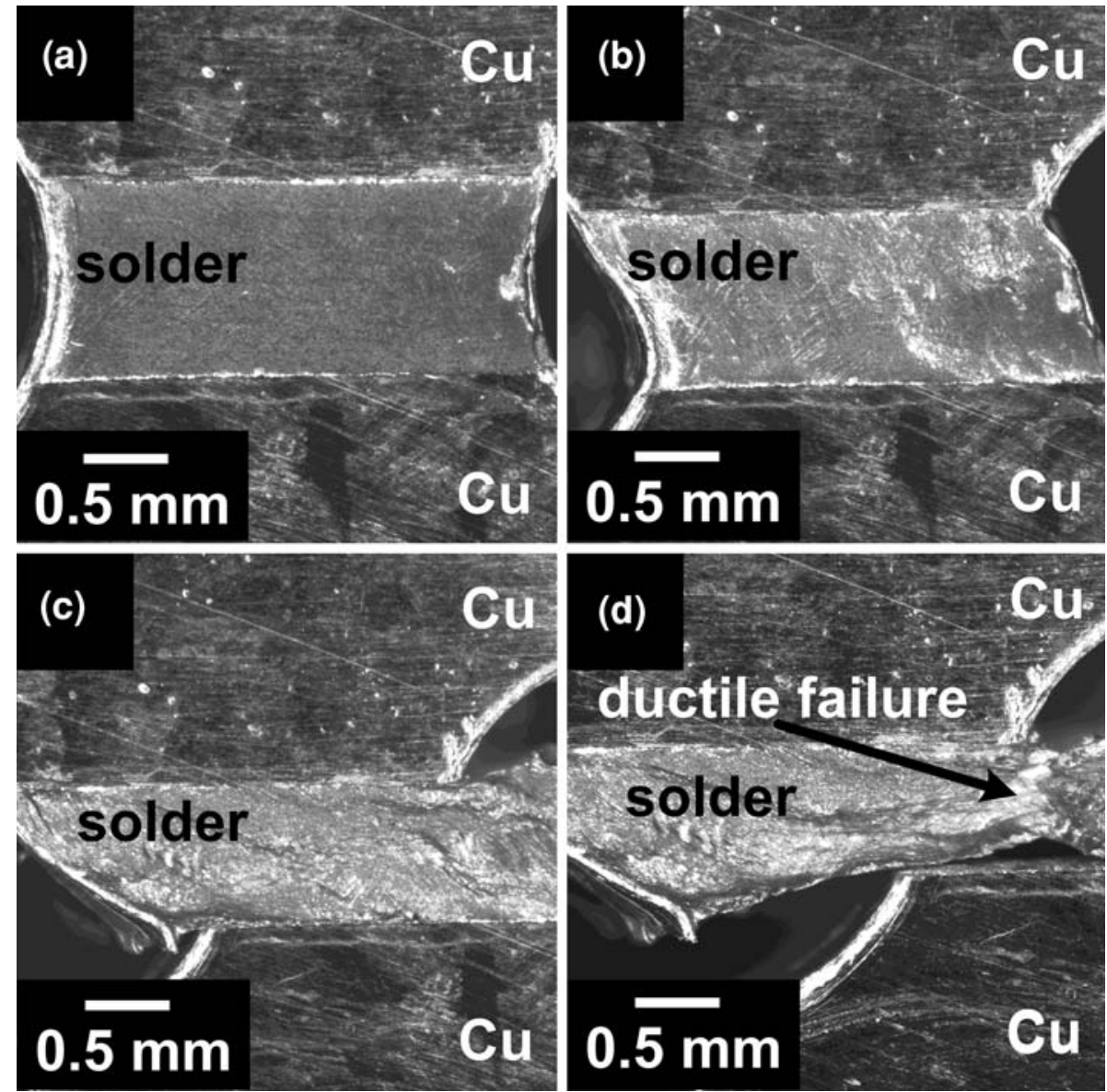

Fig. 8. In situ micrographs of SAC405 test specimen corresponding to the four different stages of the deformation process.

which displays the average stress-strain curves up to the ultimate strain. The gray solid line and the black bulleted line in Fig. 6 represent the average stress-strain response of joint specimens produced with SAC405 and SAC405+Ni, respectively. The average stress-strain curve was calculated from at least eight joint specimens for each solder material. The gray shading represents the standard deviation in the experimental data. The scatter in the experimental data is limited and leads to an uncertainty of $5 \%$ on the shear stress-strain curves. The ultimate shear stress of joints produced with SAC405+Ni is about $32.5 \mathrm{MPa}$, which is a substantial increase (about 25\%) over the corresponding value, 25.3 $\mathrm{MPa}$, for the joints produced with SAC405. The graphs of the full stress-strain curves reported in Fig. 7 show that four different regions for the shear strain can be identified, each of them related to a dominant deformation mechanism: (a) elastic, (b) plastic, (c) damage accumulation, and (d) crack propagation and failure. The in situ micrographs corresponding to the four states are shown in Figs. 8 and 9, for SAC405 and $\mathrm{SAC} 405+\mathrm{Ni}$, respectively. During the first phase of the test, stage a, both the SAC405 and the SAC405+Ni joints exhibit elastic behavior. The yield stress $\left(\sigma_{\mathrm{y}}\right)$ of the SAC405 joint specimen was measured to be $24 \mathrm{MPa}, \sim 4 \mathrm{MPa}$ lower than that observed for the SAC405+Ni joint specimen $\left(\sigma_{\mathrm{y}}=\right.$ $28 \mathrm{MPa}$ ). During stage $\mathrm{b}$, the stress-strain curve of SAC405 flattens, and plastic deformation develops with no increase in stress, whereas in SAC405+Ni a significant hardening is observed. The third stage, c, is characterized by a distinct drop in shear stress from $31 \mathrm{MPa}$ to $25 \mathrm{MPa}$ for the SAC405+Ni specimen while the stress-strain curve for SAC405 remains flat at about $24 \mathrm{MPa}$, i.e., the material deforms plastically, maintaining its shear strength. In the final phase, $d$, further increase of shear strain leads to quasibrittle failure of the SAC405+Ni specimen through crack propagation, as shown in Fig. 9. Failure initiation was primarily observed at the interfacial intermetallic layer, from which a crack propagated in the region close to the substrate/solder interface. The ultimate shear strain for the SAC405+Ni was measured to be in the range of $40 \%$ to $60 \%$. In contrast to the brittle failure observed for the SAC405+Ni specimen, SAC405 exhibited large plastic deformation and eventual ductile failure in the bulk of the solder specimen (Fig. 8d). The ultimate shear strain for the SAC405 specimen was in the range of $80 \%$ to $100 \%$. 

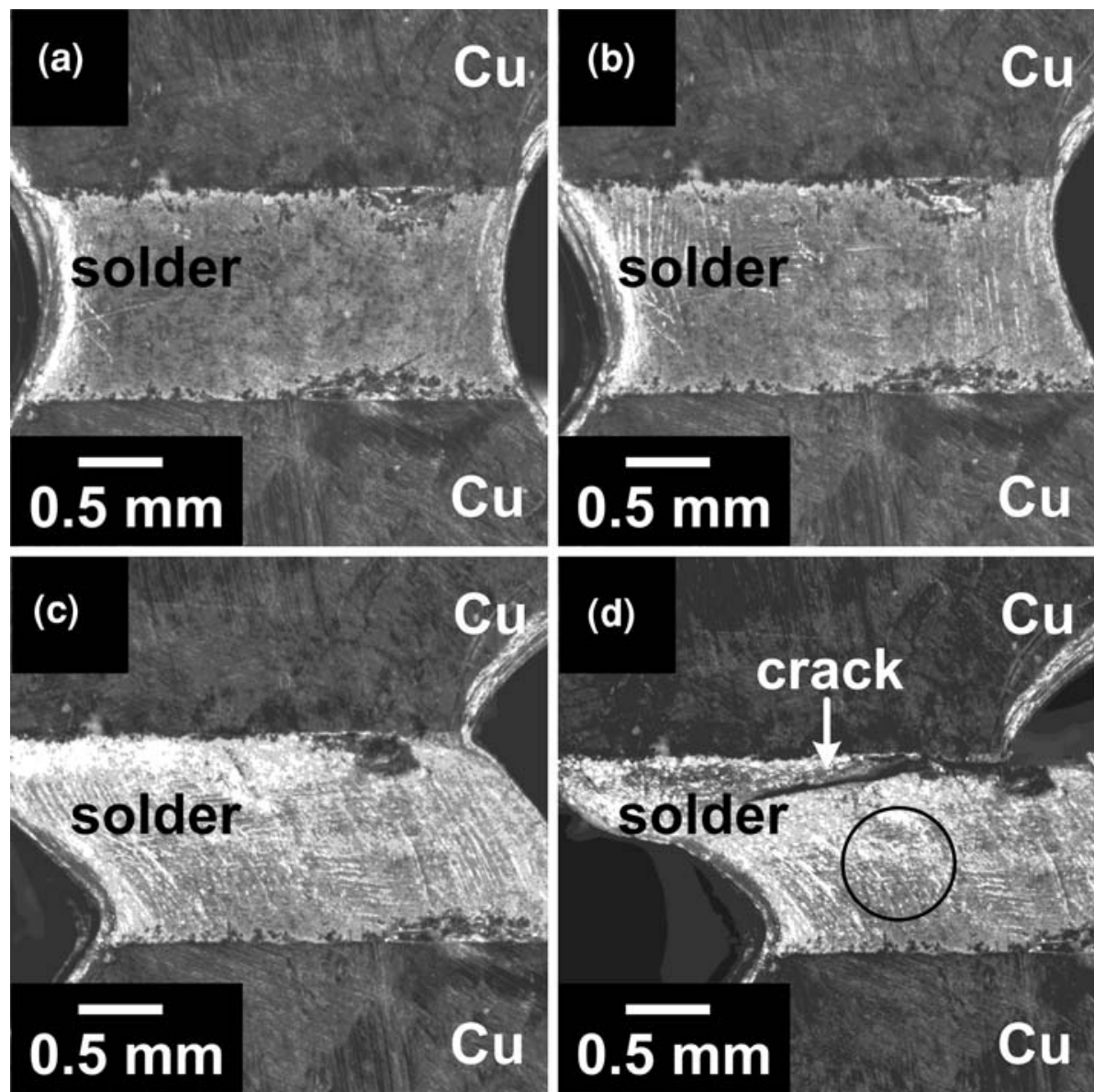

Fig. 9. In-situ micrographs of SAC405+Ni test specimen corresponding to the four different stages of the deformation process.

A typical micrograph of the central region of SAC405+Ni, the encircled region in Fig. 9d, is shown in Fig. 10. Microcracks can be observed in the Sn grains. The dark core identifiable in the $\mathrm{Sn}$ phase is constituted of reinforcing $\mathrm{Ni} / \mathrm{Ni}_{3} \mathrm{Sn}_{4}$ phases (as determined by EDS). Note that neither debonding of the reinforcing particles from the solder matrix nor failure in the Ni particles themselves can be observed.

\section{ANALYSIS}

\section{Identification of Constitutive Properties of the Solder}

The constitutive response of the solder was identified from the experimental stress-strain curve of the solder joint by means of inverse finite-element identification. The experimental load-displacement responses of the joint specimens were utilized as inputs for the identification procedure, in which an optimization loop is combined with an FE model of the experiment. The output of the identification is the stress-strain curve of the solder material that leads to the best fit with the experimental data.

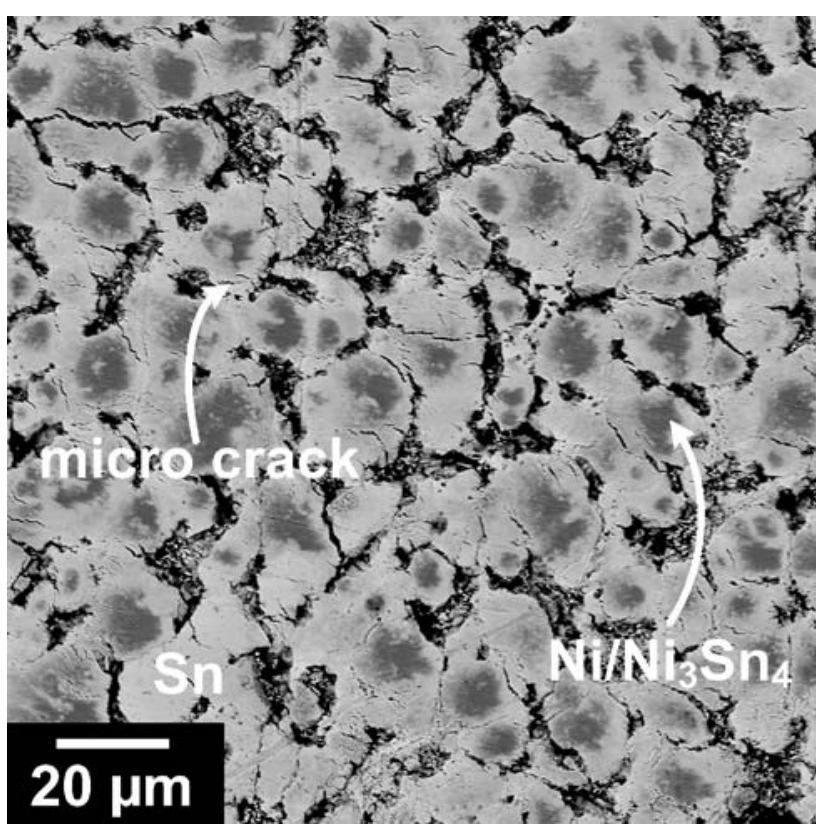

Fig. 10. Backscatter SEM image of the surface of a SAC405+Ni joint after testing. 


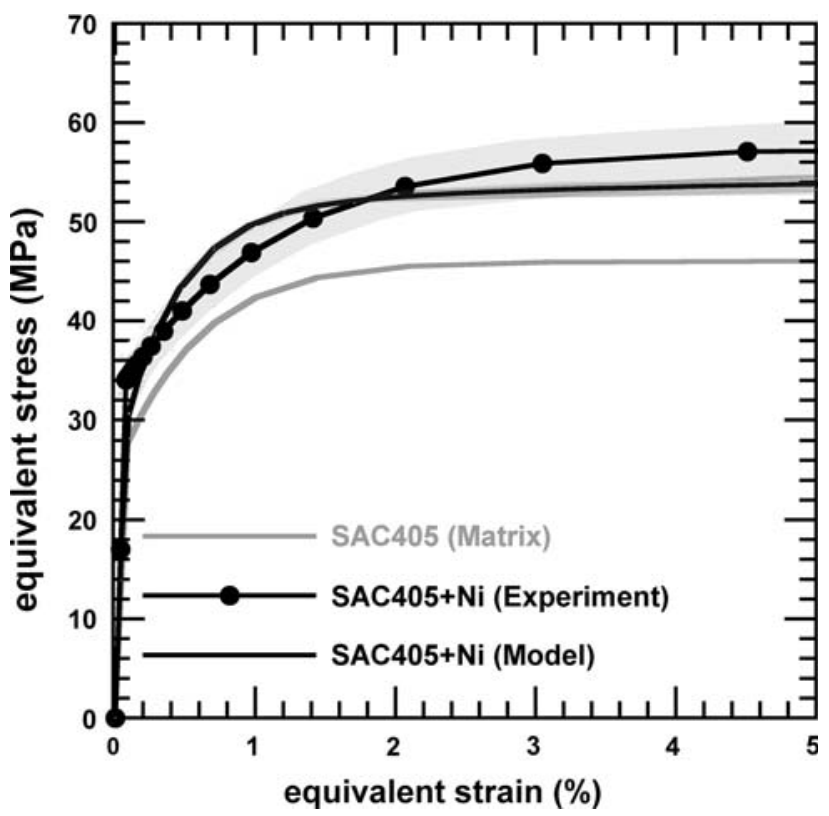

Fig. 11. Comparison of the elastoplastic stress-strain responses of SAC405+Ni specimen obtained by experiment and modeling.

A detailed description of the identification procedure is reported elsewhere. ${ }^{13}$ It is important to remark that, since the FE model represents the actual solder joint geometry, it correctly accounts for the geometrical effects on the solder joint response and thus compensates for these effects in the identification, therefore yielding the actual constitutive properties. The copper substrates are considered to be purely elastic and the solder as an elastoplastic material which follows the Von Mises yield criterion and has isotropic hardening. The isotropic hardening law used in the FE model is given by

$$
\sigma_{\mathrm{y}}=\sigma_{y}^{0}+Q^{\infty}\left[1-\exp \left(-b \varepsilon_{\mathrm{p}}\right)\right],
$$

where $\sigma_{\mathrm{y}}, \varepsilon_{\mathrm{p}}, \sigma_{\mathrm{y}}^{0}, Q^{\infty}, b$ are the yield stress, plastic strain, initial yield stress, and two hardening parameters, respectively. As damage is not modeled, the identification was carried out on the first portion of the experimental curve, up to the ultimate stress. The constitutive (uniaxial) stressstrain curves of SAC405 and SAC405+Ni are plotted in Fig. 11. The solid gray and black bulleted lines are the identified stress-strain curves of SAC405 and $\mathrm{SAC} 405+\mathrm{Ni}$, respectively. The gray shading around the black bulleted SAC405+Ni solid curve

Table I. Identified Constitutive Properties of the Solder Material (Experimental)

\begin{tabular}{|c|c|c|c|c|}
\hline Specimen & $\begin{array}{c}\sigma_{\text {yield }} \\
(\mathbf{M P a})\end{array}$ & $\begin{array}{c}\boldsymbol{Q}^{\infty} \\
(\mathbf{M P a})\end{array}$ & $\begin{array}{c}\boldsymbol{b} \\
(\mathbf{M P a})\end{array}$ & $\begin{array}{c}\sigma_{\text {ultimate }} \\
(\mathbf{M P a})\end{array}$ \\
\hline SAC40 & 27.88 & 18.13 & 186.44 & 46.01 \\
\hline $\mathrm{SAC} 405+\mathrm{Ni}$ & 34.04 & 23.44 & 91.81 & 57.49 \\
\hline
\end{tabular}

represents the $5 \%$ standard deviation in the experimental data. The corresponding identified constitutive parameters for the SAC405 and SAC405+Ni are listed in Table I. The identified ultimate stress of the $\mathrm{SAC} 405+\mathrm{Ni}$ composite specimen is $23 \%$ higher than that of SAC405. As expected, the hardening for the composite SAC405+Ni solder is significantly larger than that of the unreinforced solder.

\section{Modeling the Constitutive Response of the Composite Solder}

The material under investigation, $\mathrm{SAC} 405+\mathrm{Ni}$, is essentially a particle-reinforced metal matrix composite. The majority of the homogenization models for particulate composites reported in the literature are two dimensional. ${ }^{23-25}$ Although they capture some physical aspects of the material behavior, they are not able to predict the effective behavior of composites with randomly distributed particles. ${ }^{26,27}$ This is due to the fact that plane-stress approximations tend to underestimate the strengthening effect of the particles, whereas plane-strain ones tend to overestimate it. Therefore, in the present work a three-dimensional (3D) FE homogenization model was adopted. A detailed description of the model is reported elsewhere. ${ }^{17}$ In a direct homogenization problem, the properties of the constituents are given and the unknowns are those of the composite. Therefore, the inputs herein were the identified stress-strain response of the unreinforced solder matrix (Fig. 11) and the volume fraction (13 vol.\%) and the mechanical properties of the reinforcing phase formed due to particle addition. The output is the elastoplastic response of the $\mathrm{SAC} 405+\mathrm{Ni}$ solder. The matrix material is assumed to follow the von Mises yield criterion and have isotropic hardening. Linear elastic behavior is assigned to the reinforcement, defined by Young's modulus $(E)$ and Poisson's ratio $(v)$. The results of EDS analysis suggest that these particles are constituted of $\mathrm{Ni}_{3} \mathrm{Sn}_{4}$ intermetallics and of unreacted $\mathrm{Ni}$ particles (Fig. 4). Therefore two limit cases for particle composition were considered: $100 \% \mathrm{Ni}$ particles $(E=214 \mathrm{GPa}, v=0.3)$, as if there were no reaction of $\mathrm{Ni}$ particles with $\mathrm{Sn}$, and $100 \% \mathrm{Ni}_{3} \mathrm{Sn}_{4}$ particles $(E=133.3 \mathrm{GPa}, v=0.33)$, corresponding to the case in which all the $\mathrm{Ni}$ reacts to form $\mathrm{Ni}_{3} \mathrm{Sn}_{4}$ intermetallic particles. ${ }^{28,29}$ Perfect adhesion between particles and matrix is assumed. This assumption is supported by microscopic analyses which show neither debonding of the reinforcements from the solder matrix nor failure in the particles themselves.

The representative volume element (RVE) size was assessed using the criterion proposed in a previous study. ${ }^{17}$ In the present case, this leads to a size of a RVE that contains 121 particles. The FE model was processed with ABAQUS ${ }^{\circledR}$ Standard 6.7-1 software package ${ }^{30}$ and modified ten-node tetrahedral elements are employed. The mesh, 


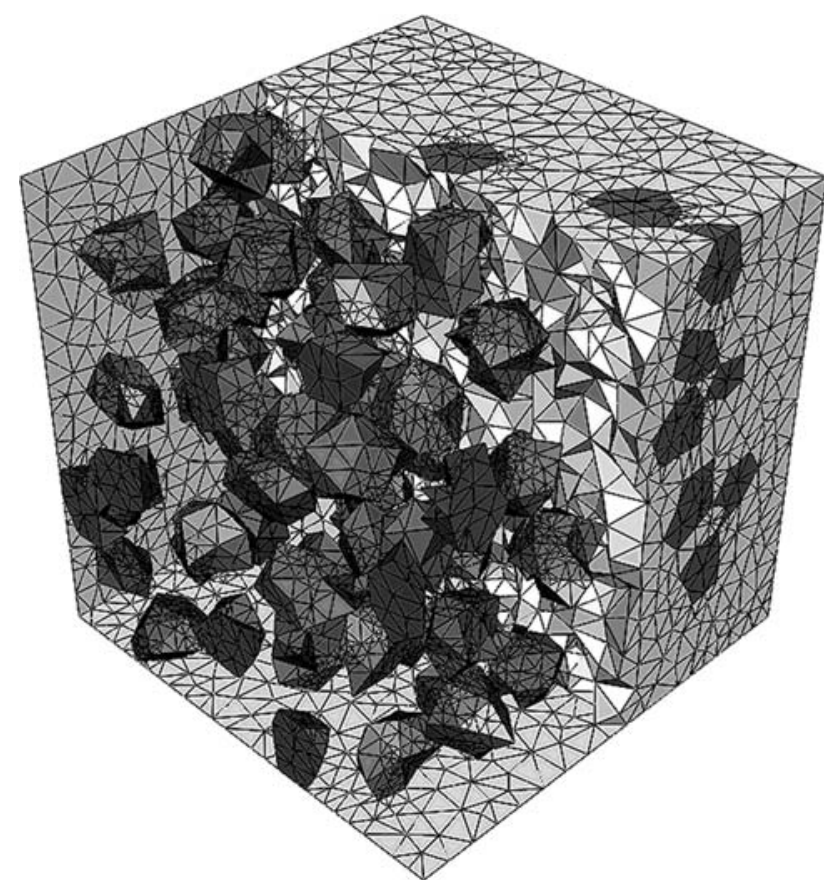

Fig. 12. The unit cell for SAC405+Ni with $13 \%$ volume of reinforcement (part of the matrix elements are not displayed to show the particles).

shown in Fig. 12, consisted of 255,802 nodes and 167,818 elements.

Pure tension simulations were carried out under mixed static-kinematic boundary conditions: the displacements were imposed at the nodes on the tensile faces and no load was imposed on the unit cell faces parallel to the tensile direction. The model predicts almost the same stress-strain curves for the composite for the two cases of the reinforcing particles considered herein. Therefore only the stress-strain curve corresponding to $100 \% \mathrm{Ni}$ particles is reported in Fig. 11. In this figure the thin dark gray shading around the stress-strain curve obtained from the model is the deviation of the model results from cubic symmetry (i.e., the difference in the response when the RVE is loaded in the $x, y$, and $z$ directions). Note that the negligible scatter provides additional proof of the representativeness of the homogenization model.

\section{DISCUSSION}

The agreement between homogenization results and experimental data (Fig. 11) leads to the conclusion that the matrix material in the composite SAC405+Ni has comparable mechanical properties to the original SAC405. The model predictions are in very good agreement with the experiments for values of the effective total strain larger than $1 \%$, with the model curve exhibiting an ultimate stress of about $51 \mathrm{MPa}$. In the regime of large plastic strain the predicted curve is slightly lower than the experimental curve, particularly with regard to the

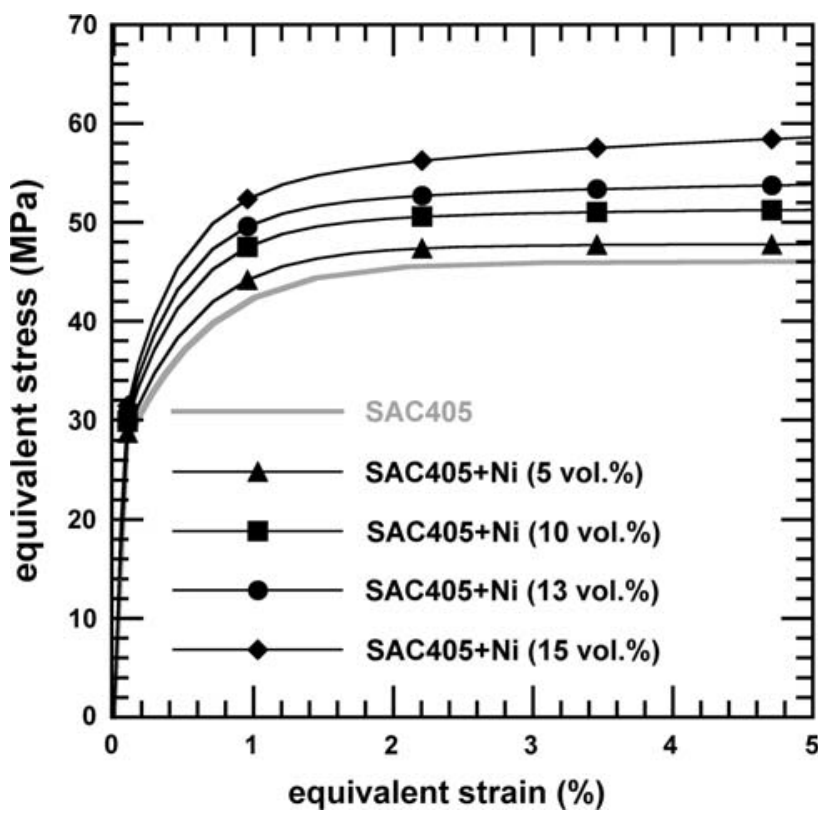

Fig. 13. Equivalent stress versus equivalent strain response of SAC405+Ni specimen obtained by homogenization with varying volume fraction of $\mathrm{Ni} / \mathrm{Ni}_{3} \mathrm{Sn}_{4}$ reinforcing phases.

ultimate stress, but the difference is on the order of the error in the experimental test data. A small difference can be noticed in the shape of the hardening part of the stress-strain curve when the total strain is less than $1 \%$. This discrepancy is caused by imperfect identification of the constitutive response of the Ni-reinforced solder: the exponential hardening model used in the inverse method cannot reproduce the initial strong hardening experimentally observed for SAC405+Ni.

The fact that the 3D continuum-based homogenization model captures the elastoplastic response of the composite solder further leads to the conclusion that the strengthening effects in the composite SAC405+Ni are mainly due to load sharing between particles and to the development of a significant triaxial stress state in the solder matrix, which impedes plastic deformation. Therefore, strengthening effects related to pinning of dislocations are negligible. This can be attributed to the fact that the characteristic size of the reinforcement is relatively large ${ }^{31,32}>5 \mu \mathrm{m}$, as shown in Fig. 3 .

As expected, the increase in the material strength is accompanied by a loss of ductility, as confirmed by experimental data. Failure initiation at the thick interfacial intermetallic layer between the solder and base metal in the SAC405+Ni joints suggests the presence of stress concentrations, possibly due to the fact that the interfacial intermetallic layer is thicker than in the case of the joints with SAC405. The microcracks propagating in the $\mathrm{Sn}$ grains (Fig. 10) suggest the presence of high stresses in the Sn-based matrix, caused by the presence of the reinforcement. By contrast, the absence of reinforcing phases in the SAC405 joints leads to their 
very ductile behavior with unrestricted plastic flow up to the observed $80 \%$ to $100 \%$ ultimate shear strain. Other studies have also observed an increase in strength and loss in ductility upon adding metallic/ceramic reinforcements to solders. ${ }^{33-35}$

Further homogenization analyses were carried out to predict the properties of the composite as a function of the reinforcement volume fraction ( 5 vol.\% to 15 vol.\%). The results summarized in Fig. 13 show that the material strength is proportional to the reinforcement volume fraction. However it can be observed that at least $10 \mathrm{vol} . \%$ of reinforcing phases are required to observe a substantial increase in the ultimate strength. These results also show that homogenization techniques can help to minimize the experimental work required to optimize the reinforcement volume fraction.

\section{CONCLUSIONS}

A combined experimental and modeling approach was successfully applied to investigate the mechanical response of composite lead-free solder SAC405+Ni. The solder joints were tested in shear using a novel specimen design which provides accurate and realistic experimental results. The additional phases formed in the solder due to particle addition lead to an increase in the strength of the solder, accompanied by a loss in ductility. This effect can be explained by taking into account the mechanism of load sharing between matrix material and reinforcement and the restricted plastic flow of the solder matrix caused by the presence of the stiff inclusions. Since no significant size effect can be observed, the elastoplastic response of the composite can be accurately predicted using a 3D homogenization model, which proves to be a powerful tool able to guide, and therefore minimize, the experimental activity. Future steps following the present work include the development of tools for the prediction of the ductility limits and the creep response of composite solders. These would require the incorporation of complex damage mechanisms involving void growth and coalescence, as well as detailed creep models of the constituents.

\section{ACKNOWLEDGEMENTS}

This research was performed in the framework of COST 531 Action: Lead-Free Solder Materials and was supported by the Swiss State Secretariat for Education and Research (SER) Grant C03.0026. Author V. Sivasubramaniam would like to express his gratitude to Dr. N.S. Bosco and Mr. V. Bissig for their help in experiment planning and stimulating discussions.

\section{REFERENCES}

1. M. Abtew and G. Selvaduray, Mater. Sci. Eng. Rep. 27, 95 (2000).

2. K.N. Subramanian, A. Lee, S. Choi, and P. Sonje, J. Electron. Mater. 30, 372 (2001).

3. K.N. Tu, A.M. Gusak, and M. Li, J. Appl. Phys. 93, 1335 (2003).

4. K. Suganuma, Curr. Opin. Solid State Mater. Sci. 5, 55 (2001).

5. F. Guo, J. Mater. Sci. Mater. Electron. 18, 129 (2007).

6. J.S. Lee, K.M. Chu, D.Y. Jeon, R. Patzelt, D. Manessis, and A. Ostmann, Proceedings of the 56th Electronic Components and Technology Conference (IEEE, 2006), pp. 244-249.

7. K. Mohankumar and A.A.O. Tay, Proceedings of 6 th Electronics Packaging Technology Conference (IEEE, 2004), pp. $455-461$.

8. J.P. Liu, F. Guo, Y.F. Yan, W.B. Wang, and Y.W. Shi, J. Electron. Mater. 33, 958 (2004).

9. D.C. Lin, C.Y. Kuo, T.S. Srivatsan, and G.X. Wang, Proceedings of the ASME Heat Transfer Division, vol. 3, Heat Transfer Equipment, Heat Transfer in Manufacturing and Materials Processing (2003), pp. 253-258.

10. Y. Shi, J. Liu, Y. Yan, Z. Xia, Y. Lei, F. Guo, and X. Li, J. Mater. Sci. Mater. Electron. 37, 507 (2008).

11. K.N. Tu, Solder Joint Technology (Springer, 2007).

12. Y.L. Shen, N. Chawla, E.S. Ege, and X. Deng, Acta Mater. 53, 2633 (2005).

13. J. Cugnoni, J. Botsis, V. Sivasubramaniam, and J. JanczakRusch, Fatigue Fract. Eng. Mater. Struct. 30, 387 (2007).

14. J. Cugnoni, J. Botsis, and J. Janczak-Rusch, Adv. Eng. Mater. 8, 184 (2006).

15. Y. Kim, K. Kim, C. Hwang, and K. Suganuma, J. Alloys Compd. 352, 237 (2003).

16. X. Deng, G. Piotrowski, J.J. Williams, and N. Chawla, J. Electron. Mater. 32, 1403 (2003).

17. M. Galli, J. Botsis, and J. Janczak-Rusch, Comput. Mater. Sci. 41, 312 (2008).

18. J.G. Lee, F. Guo, K.N. Subramanian, and J.P. Lucas, Solder. Surf. Mt. Technol. 14, 11 (2002).

19. V. Sivasubramaniam, N.S. Bosco, J. Janczak-Rusch, J. Cugnoni, and J. Botsis, J. Electron. Mater. 37, 1598 (2008).

20. H.S. Liu, J. Wang, and Z.P. Jin, Calphad 28, 363 (2004).

21. F. Guo, J. Lee, S. Choi, J.P. Lucas, T.R. Bieler, and K.N. Subramanian, J. Electron. Mater. 30, 1073 (2001).

22. S. Choi, T.R. Bieler, J.P. Lucas, and K.N. Subramanian, J. Electron. Mater. 28, 1209 (1999).

23. H.D. Espinosa and P.D. Zavattieri, Mech. Mater. 35, 333 (2003).

24. N. Chawla, X. Deng, and D.R.M. Schnell, Mater. Sci. Eng. A 426, 314 (2006).

25. A. Borbely, H. Biermann, and O. Hartmann, Mater. Sci. Eng. A 313, 34 (2001).

26. T. Iung and M. Grange, Mater. Sci. Eng. A 201, L8 (1995).

27. H.J. Böhm and W. Han, Model Simul. Mater. Sci. Eng. 9, 47 (2001).

28. http://www.matweb.com.

29. NIST: http://www.metallurgy.nist.gov/mechanical_properties/ roomtemp_properties.jpg.

30. ABAQUS 6.5 Analysis User's Manual.

31. N. Ramakrishnan, Acta Mater. 44, 69 (1996).

32. M. Kouzeli and A. Mortensen, Acta Mater. 50, 39 (2002).

33. X.L. Zhong and M. Gupta, Adv. Eng. Mater. 7, 1049 (2005).

34. K.S. Kim, S.H. Huh, and K. Suganuma, J. Alloys Compd. 352,226 (2003).

35. K. Mohankumar, V. Kripesh, and A.A.O. Tay, Proc. Electron. Comp. Technol. Conf., vol. 56, issue 30 (IEEE, 2006), pp. $237-243$. 